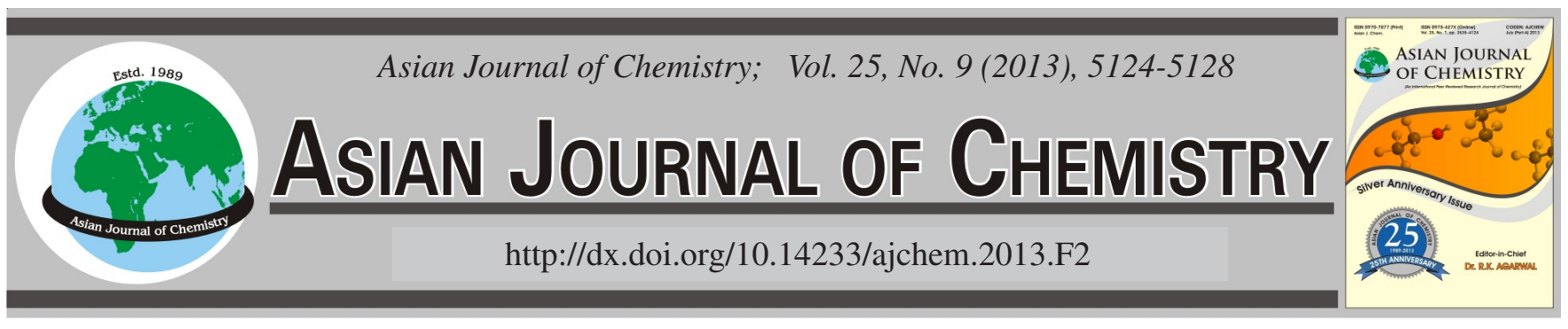

\title{
Modification of Polymer Properties by Irradiation Properties of Thermoplastic Electromer after Radiation Cross-linking $\dagger$
}

\author{
M. Manas*, D. Manas, M. Stanek, A. Mizera and M. Ovsik
}

Department of Production Engineering, Faculty of Technology, Tomas Bata University in Zlin, 76001 Zlin, Czech Republic

*Corresponding author: Fax: +420 57603 5176; Tel: +420 602785726; E-mail: manas@ft.utb.cz

Radiation processing involves the use of natural or manmade sources of high energy radiation on an industrial scale. The principle of radiation processing is the ability of high energy radiation to produce reactive cations, anions and free radicals in materials. The industrial applications of the radiation processing of plastics and composites include polymerization, cross-linking, degradation and grafting. Radiation processing involves mainly the use of either electron beams from electron accelerators or $\gamma$-radiation from cobalt- 60 sources. The TPE-E thermoplastic elastomer tested exhibited significant changes in temperature stability and mechanical properties after irradiation. From this point of view, there may be new applications in areas with service temperatures higher than their former melting point. This study compared the temperature stability and mechanical properties of irradiated and non-irradiated TPE-E.

Key Words: Thermoplastic elastomer, Irradiation, Properties.

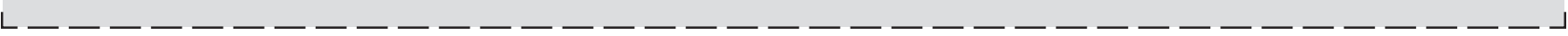

\section{INTRODUCTION}

The cross-linking of rubber and thermoplastic polymers is a well-proven process for improving the thermal properties. Chemical cross-linking or rubber vulcanization is normally induced by heating after processing in the presence of a curing agent. The cross-linking process for thermosets is quite similar. In thermosets, the polymer molecules are also linked chemically due to heat after processing. Cross-linked rubbers have a wide-meshed molecular network that keeps them soft and their properties change only slightly over a wide temperature range. On the other hand, thermosets are characterized by a very narrow-meshed network. Therefore, they barely change their high level of stiffness over a wide temperature range. The irradiation cross-linking of thermoplastic materials via an electron beam or cobalt 60 ( $\gamma$-rays) is performed separately after processing. Ionizing radiation includes accelerated electrons, $\boldsymbol{\gamma}$-rays and $\mathrm{X}$-rays ${ }^{1}$. These are not only capable of converting monomeric and oligomeric liquids, but can also cause major changes in the properties of solid polymers through cross-linking. The cross-linking level can be adjusted by the irradiation dose. The absorbed dose means the value of energy of ionizing radiation absorbed per unit of mass of the processed material. The unit of absorbed dose is 1 gray ( $1 \mathrm{~Gy}$ $=1 \mathrm{~J} / \mathrm{kg}$ ). The main difference between $\beta$ and $\gamma$-rays is in their ability to penetrate the irradiated material. $\gamma$-Rays have a high penetration capacity, whereas the penetration capacity of electron rays depends on the energy of the accelerated electrons. With electron accelerators, the required dose can be applied within seconds, whereas several hours are needed in a $\gamma$-radiation plant. Another difference between $\beta$ and $\gamma$-rays is in their different distribution in space. $\gamma$-Rays are distributed from the source in all directions, whereas $\beta$-rays are strictly oriented only to the irradiated material (Fig. 1) 1,2 $^{\text {. }}$

$\beta$ - and $\gamma$-rays can be used for the irradiation of polyolefines, polyesters, halogen polymers and polyamides from the thermoplastics group, elastomers and thermoplastic elastomers. Some of them require the addition of a cross-linking agent. The dimensional stability, strength, chemical resistance and wear of polymers can be improved by irradiation ${ }^{1,3-5}$. Radiation cross-linking produces inexpensive commodity plastics and technical plastics with the mechanical, thermal and chemical properties of high-performance plastics ${ }^{2}$. Irradiation crosslinking normally creates a higher strength and reduced creep under load and leads to a huge improvement in resistance to most of the chemicals, which often leads to improvements in wear behaviour ${ }^{1,6}$. Radiation processing with an accelerating beam offers several advantages compared to other radiation sources, particularly $\gamma$-rays and X-rays. The process is quite fast, clean and can be controlled with a great deal of precision. 

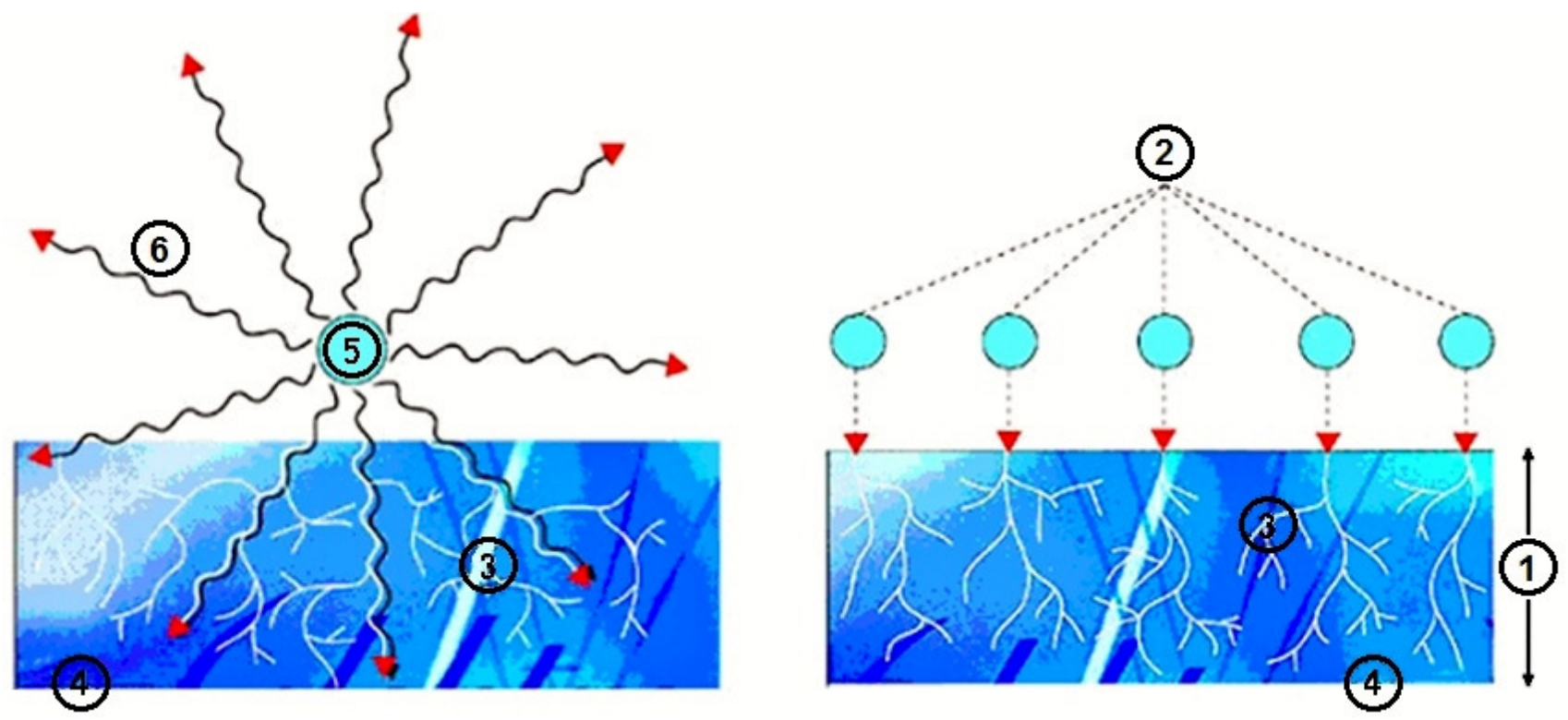

Fig. 1. Design of $\gamma$-Rays (a) and electron rays (b); a) 3-Secondary electrons, 4-Irradiated material, 5-Encapsulated Co-60 radiation source, 6- $\gamma$-Rays; b) 1- Penetration depth of an electron, 2-Primary electron, 3-Secondary electron, 4-Irradiated material [Source: BGS]

In contrast to $\gamma$-rays and $\mathrm{X}$-rays, the electron beam can be steered relatively easily, thereby allowing the irradiation of a range of physical shapes. The electron beam radiation process is practically free of waste products and therefore poses no serious environmental hazard ${ }^{1}$.

The thermoplastics used in the production of various types of products have different properties. Thermoplastic elastomers (TPEs) are a special group of polymers that exhibit elastic behaviour similar to that of a vulcanized conventional elastomer and can be processed as thermoplastics (i.e. by melt processing). Most thermoplastic elastomers are essentially phase-separated systems. Normally, one phase is hard and solid at ambient temperature, whereas the other is an elastomer. Often, the phases are bonded chemically by block or graft polymerization. In other cases, a fine dispersion of the phases is apparently sufficient. The hard phase gives these TPEs their strength and represents physical crosslinking. Without it, the elastomer phase would be free to flow under stress and the polymer would be practically unusable. On the other hand, the elastomer phase imparts flexibility and elasticity to the system. When the hard phase is melted, the material can flow and be processed by normal processing methods. Upon cooling, the hard phase solidifies and the material regains its strength and elasticity ${ }^{7,8}$.

The individual polymers constituting the respective phases retain most of their characteristics so that each phase exhibits its specific glass transition temperature $\left(\mathrm{T}_{\mathrm{g}}\right)$ or crystalline melting temperature $\left(\mathrm{T}_{\mathrm{m}}\right)$. These two temperatures determine the points at which the particular elastomer goes through the transition in its physical properties. The service temperature range lies between $T_{g}$ of the elastomeric phase (lower service temperature) and the $\mathrm{T}_{\mathrm{g}}$ or $\mathrm{T}_{\mathrm{m}}$ of the hard phase (upper service temperature). The precise values depend on the service condition of the final product. Therefore, the actual lower service temperature will often be higher than the $T_{g}$ of the elastomer and the actual upper service temperature will be lower than the $T_{g}$ or $T_{m}$ of the hard phase ${ }^{7}$. In this study, an engineering polyester thermoplastic elastomer was tested. One of this material's distinguishing features is its high flexibility and good thermal resistance, even at higher temperatures. The flexural and fatigue strength are both very good, even at low temperatures. Hard/soft combinations can be formed with ABS, ABS/ PC blends and with PC and PBT. After irradiation the thermoplastic elastomer has changed and its mechanical behaviour is closer to that of elastomers than to thermoplastics. Therefore, the advantages of a thermoplastic elastomer in processing are combined with the properties of an elastomer.

Compared to other construction/engineering materials, mainly metals, polymers including TPEs have limited mechanical and thermal properties, which reduce their applicability significantly. Every improvement in these properties improves their applicability. The irradiation of thermoplastics is an important way of changing their thermal properties. From a usage pointof-view, the temperature stability is a very important factor. Plastic parts suitable for radiation cross-linking are extruded products like tubes, pipes and profiles as well as injectionmolded parts.

\section{EXPERIMENTAL}

The mechanical properties and thermal stability of an irradiated thermoplastic elastomer after irradiation were tested. An ARBURG Allrounder 420C Advance Injection molding machine was used for sample preparation according to the TPE-E producer's recommendations.

Polymers used: TPE-E, V-PTS-UNIFLEX-E25D/ M*M800/20 natur ${ }^{8}$.

Tensile test: The tensile strength test was conducted on a T 2000 Alpha Technologies testing machine, under a constant elongation speed of $500 \mathrm{~mm} / \mathrm{min}$. The testing samples used were in the shape of a shovel and their dimensions complied with the CSN ISO 37 standards.

Tear test: The tear strength was measured using a T 2000 Alpha Technologies tensile test machine. The test was carried out under a constant speed of elongation of $500 \mathrm{~mm} / \mathrm{min}$. The tear strength was measured using methods A "Trousers" and 
B "Angle" according the ISO 34-1 standard (similar Standard ASTM D 624 Die C "Graves").

Hardness test: The hardness was measured using a HPE - A Berreiss hardness tester type and the Shore A Method. The shape and dimensions of the testing samples were in accordance with the CSN 621431 standard.

Micro-hardness test: Instrumented micro-hardness tests were performed using a Micro Combi Tester, CSM Instruments (Switzerland), in line with the CSN EN ISO 6507-1 norms. The load and unload speed was $2 \mathrm{~N} / \mathrm{min}$. After a holding time of $90 \mathrm{~s}$ at a maximum load of $1 \mathrm{~N}$, the specimens were unloaded. The indentation hardness $\mathrm{H}_{\text {IT }}$ was calculated to be the maximum load $F_{\max }$ on the projected area $A_{p}$ of the hardness impression according to the following equations:

$$
\mathrm{H}_{\mathrm{IT}}=\frac{\mathrm{F}_{\max }}{\mathrm{A}_{\mathrm{p}}} \quad \text { with } \mathrm{h}_{\mathrm{c}}=\mathrm{h}_{\max }-\varepsilon \frac{\mathrm{F}_{\max }}{\mathrm{S}}
$$

where $\mathrm{h}_{\max }$ is the indentation depth at $\mathrm{F}_{\max }, \mathrm{h}_{\mathrm{c}}$ is the contact depth and $\varepsilon$ is the indentor geometric constant. In this study, the Oliver and Pharr method was used to calculate the initial stiffness $(\mathrm{S})$ and contact depth $\left(\mathrm{h}_{\mathrm{c}}\right)$. The specimens were glued onto metallic sample holders. The indentation creep was measured as the change in the indentation depth under a constant force during the test period.

Thermomechanical analysis (TMA): Equipment: Perkin -Elmer Thermal Analyser TMA 7; Heat from $50{ }^{\circ} \mathrm{C}$ to $400{ }^{\circ} \mathrm{C}$ at $20^{\circ} \mathrm{C} / \mathrm{min}$; Hold for $1 \mathrm{~min}$ at $50^{\circ} \mathrm{C}$.

Irradiation of the TPE-E polymer tested was performed with the kind help of BGS Germany, in the BGS Wiehl plant using accelerated electrons with a dosage range of 0 to $198 \mathrm{kGy}$.

\section{RESULTS AND DISCUSSION}

The mechanical and thermal behaviour of thermoplastic elastomers (TPE-E), before and after irradiation, was studied. Dimensionless values (-) were used in some cases to simplify the evaluation of the measured data and compare the irradiated polymer with a non irradiated one. The properties of the nonirradiated polymer had a dimensionless value of 1 , whereas the others were expressed as the ratio of measured property of irradiated polymers to the same property of the non-irradiated polymer.

Tensile strength and elongation: Irradiation affects the mechanical properties of the TPE-E studied. The tensile strength increased by more than $35 \%$ after irradiation with a dose of $66 \mathrm{kGy}$. Although the gel content increased with the irradiation dose, the tensile strength decreased with doses $>66$ $\mathrm{kGy}$. With a dosage of $132 \mathrm{kGy}$ and higher, the tensile strength oscillated around the value of the non-irradiated polymer. From the point-of-view of its tensile strength, an irradiation dose of $66 \mathrm{kGy}$ would appear to be optimal (Fig. 2.).

Elongation of the TPE-E decreased continually in line with the irradiation dosage. At the highest applied irradiation dose (i.e. $198 \mathrm{kGy}$ ), the elongation was only $25 \%$ of the former (non-irradiated) polymer. The TPE-E studied loses its flexibility due to irradiation (Figs. 3 and 4).

The modulus of elasticity increases gradually in line with the irradiation dose. The Modulus 100 and Modulus 300 was $25 \%$ higher and more than $50 \%$ higher, respectively, after irradiation with a dose of $198 \mathrm{kGy}$ (Fig. 5).

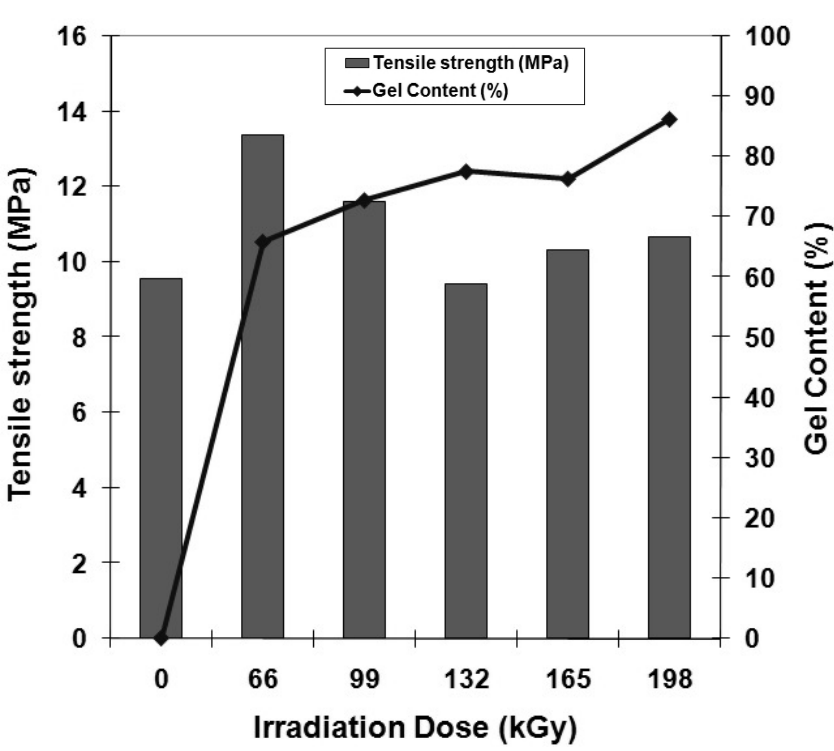

Fig. 2. Effect of irradiation on the tensile strength

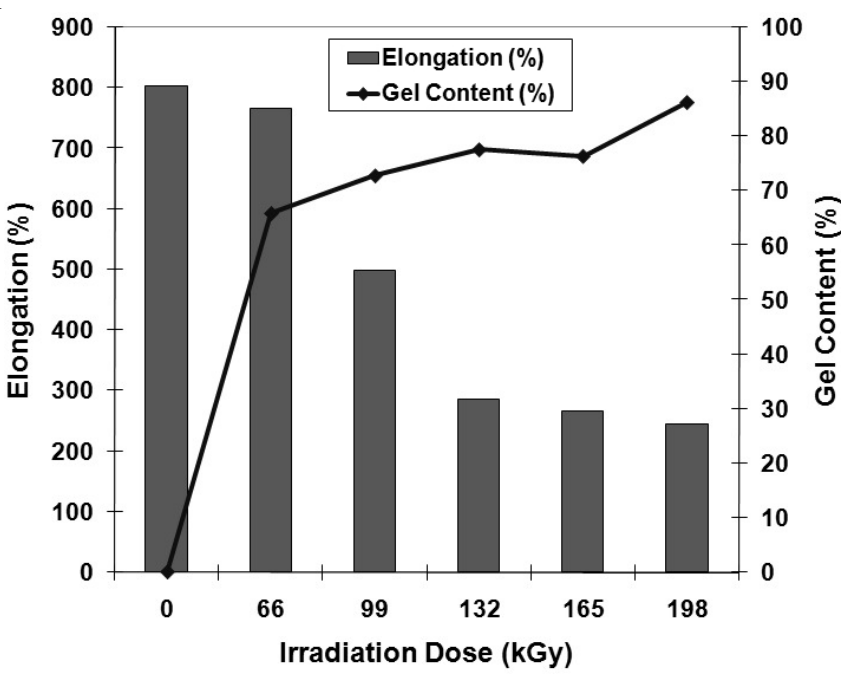

Fig. 3. Effect of irradiation on the TPE-E elongation

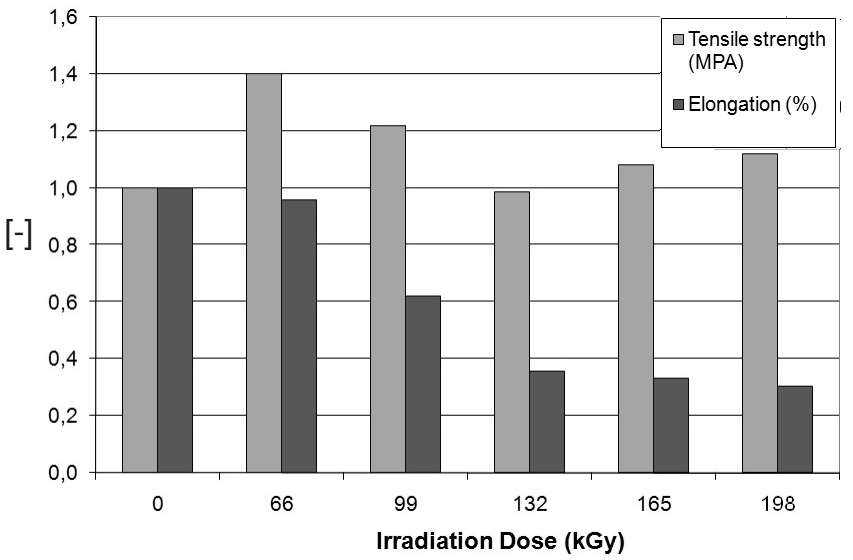

Fig. 4. Comparison of the TPE-E tensile strength and elongation irradiation

Tear strength: Irradiation also affects the tear strength. The tear strength (i.e. method A "Trousers") decreased rapidly with increasing irradiation dose. At the lowest applied irradiation dose (66 kGy), the tear strength (Trouser test) was approximately $75 \%$ lower than that of the former ( not irradiated) polymer. In contrast to the Trouser test, irradiation had a positive effect 
on the tear strength measured by method B "Angle". The best results were achieved using a dose of $66 \mathrm{kGy}$. Subsequently, the tear strength continued to decrease constantly. In the case of irradiation with a dose of $66 \mathrm{kGy}$, the tear strength was approximately $120 \%$ higher than that of the former polymer. In addition, at the highest applied irradiation dose, the tear strength according method B was approximately $40 \%$ higher than that of the non-irradiated TPE-E (Fig. 6).

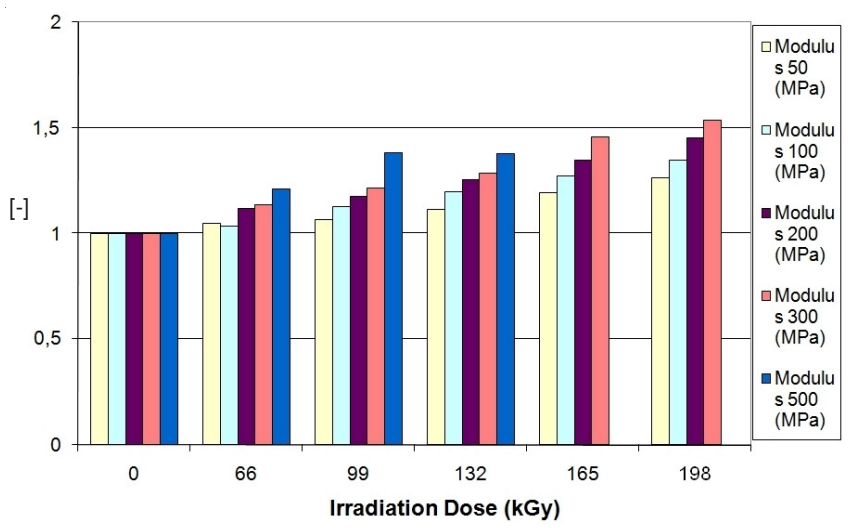

Fig. 5. Comparison of the TPE-E's E-modulus Irradiation

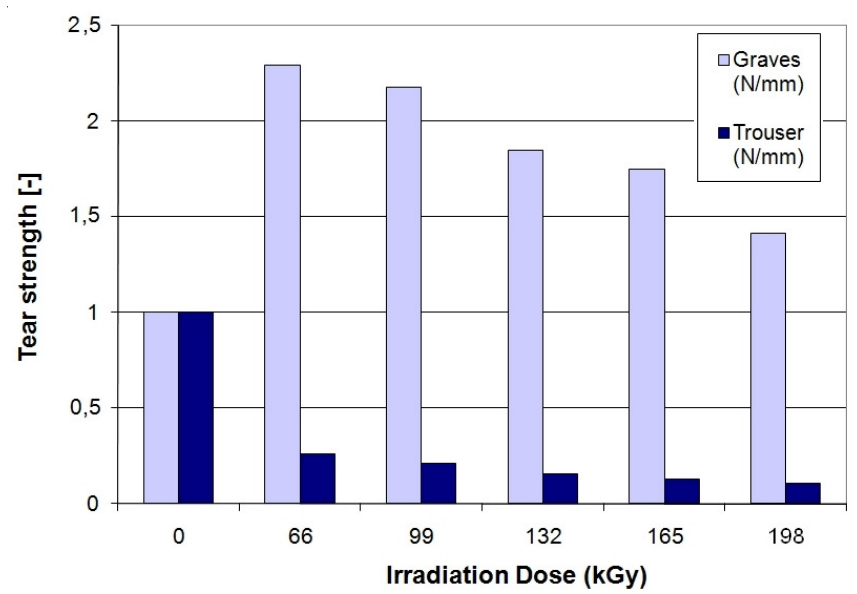

Fig. 6. Comparison of the TPE-E tear strength after irradiation

Hardness: No significant changes in hardness were observed after irradiation of the sample TPE-E. A maximum increase in hardness (i.e. ca. $15 \%$ ) was measured after a irradiation dose of $66 \mathrm{kGy}$. Higher irradiation doses had no significant effects on the Shore A hardness (Fig. 7).

Micro-hardness: The micro-hardness (indentation micro-hardness), creep and elastic modulus were examined using micro-hardness indentation techniques. Irradiation affects the micro-hardness. The difference between an irradiated and non-irradiated polymer reaches approximately $30 \%$ with a dose of $198 \mathrm{kGy}$ (Fig. 8).

From Fig. 9, it is obvious that irradiation has a positive effect on the creep behaviour of the TPE-E tested. The highest difference in indentation creep was observed for an irradiation dose of $198 \mathrm{kGy}$. These findings are quite important from the point-of-view of TPE-E use as a construction polymer.

The tendency for changes in the elastic modulus in line with the irradiation dosage was measured using the indentation method (Fig. 10) and corresponds very well to the elastic

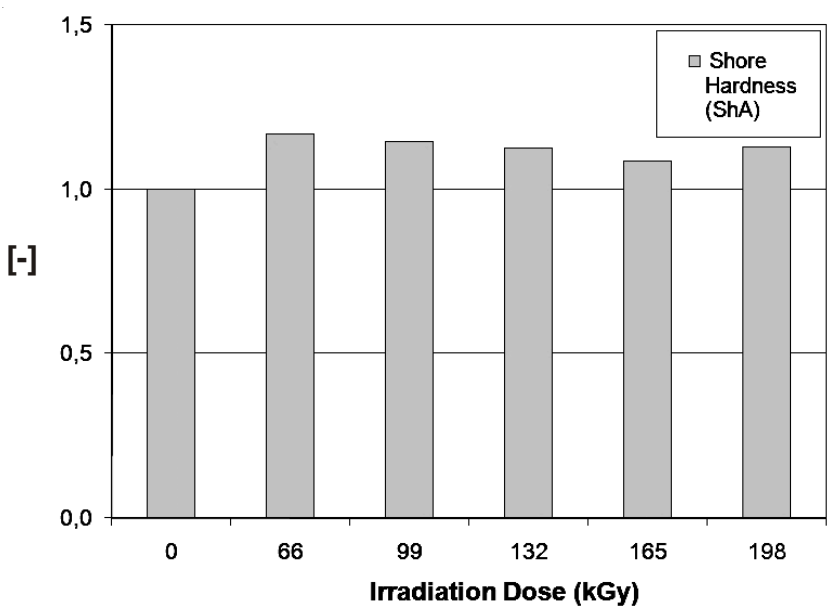

Fig. 7. Comparison of the TPE-E hardness after irradiation

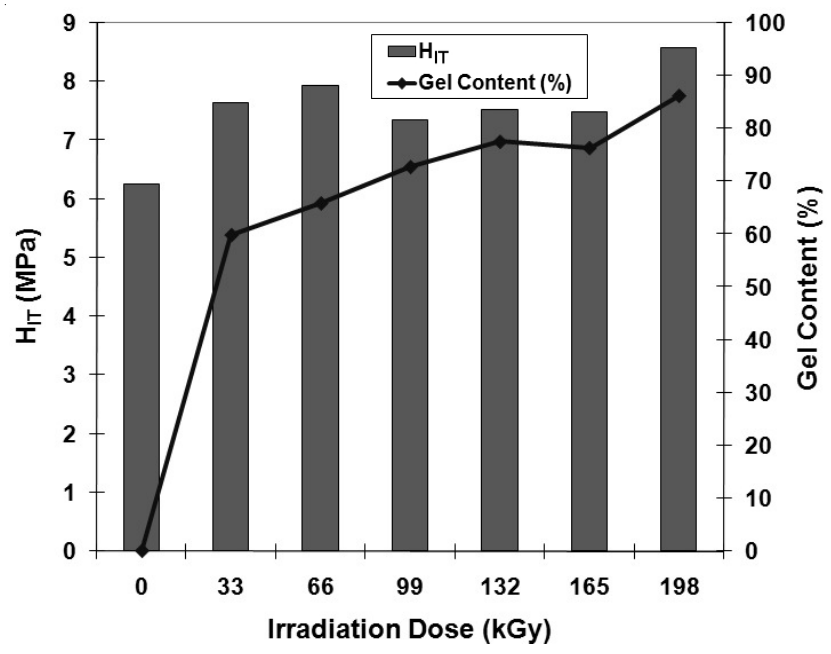

Fig. 8. TPE-E Indentation micro-hardness after irradiation

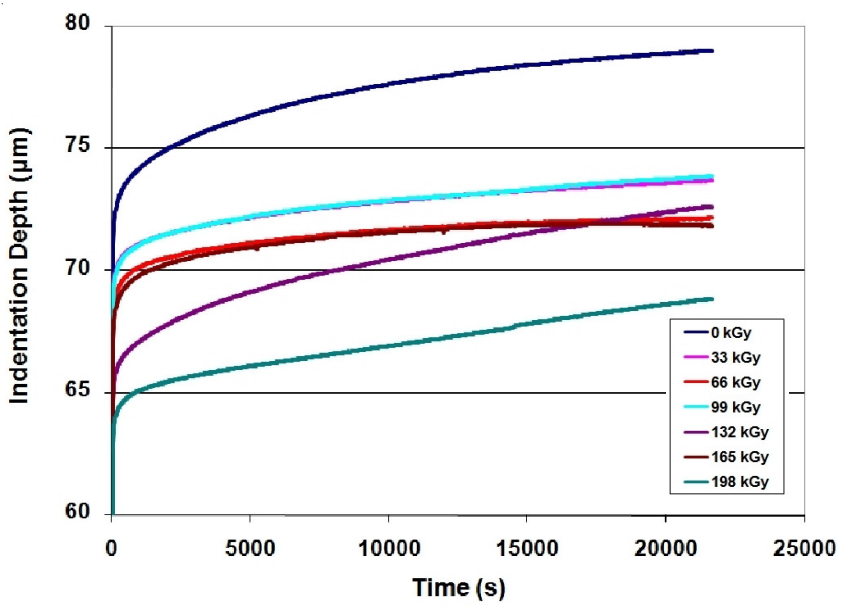

Fig. 9. TPE-E creep behaviour

modulus measured from the tensile test (Fig. 5). Therefore, Micro/Nano indentation methods are useful tools for characterizing the mechanical behaviour of polymers.

Temperature stability: The temperature stability of polymers is very low compared to other construction materials. The experiments performed in this project showed that irradiation cross-linking significantly affects the temperature stability of the TPE-E studied. The temperature stability of 
these polymers improved with increasing irradiation dose. The tested specimen showed no dimensional changes at $200{ }^{\circ} \mathrm{C}$ after irradiation with more than $165 \mathrm{kGy}$ (Figs. 11 and 12). The same specimen at temperatures $>250{ }^{\circ} \mathrm{C}$ showed colour changes due to thermal oxidation but its dimension/crosssection showed no change. The better temperature stability makes it possible to use irradiated polymers, even at service temperatures higher than its former melting point (melting point of non-irradiated polymer).

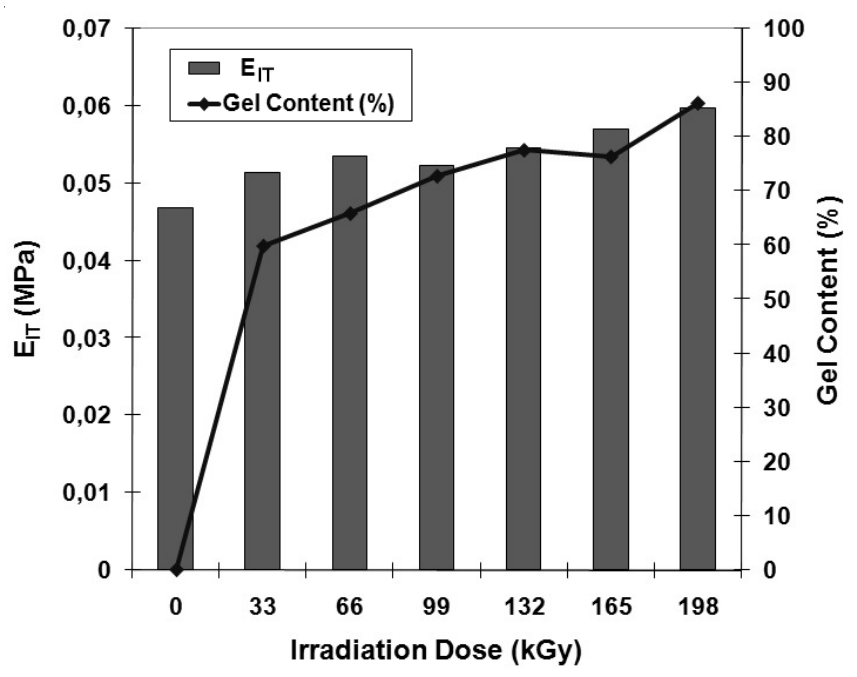

Fig. 10. TPE-E elastic modulus after irradiation

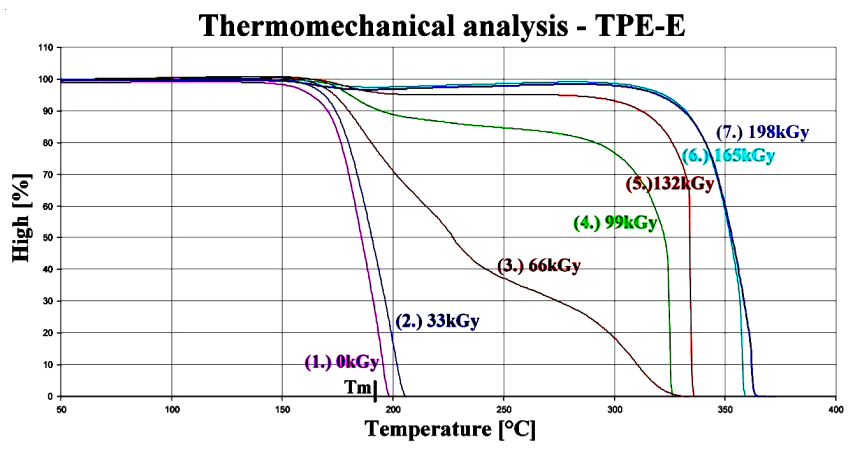

Fig. 11. TPE-E TMA analysis

TPE-E $\left[t=140 \mathrm{~min}, \mathrm{~T}=200^{\circ} \mathrm{C}\right]$

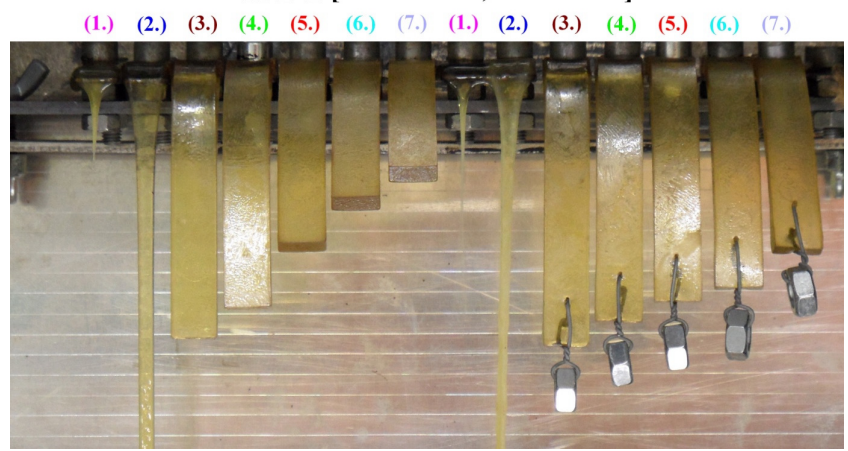

Fig. 12. Photograph of the TPE-E temperature stability, after irradiation

\section{Conclusion}

The irradiation of polymers is a simple process leading to an improvement in properties. In many cases, some properties of irradiated standard polymers are on a level that will enable them to replace much more expensive technical polymers. The main reason for the improvements in the properties of irradiated polymers was the formation of new chemical bonds between the macromolecules forming a three -dimensional network. The irradiated polymer losses the properties of thermoplastics and becomes a polymer with properties closer to the thermosets.

The results of the measurements of TPE-E after irradiation showed significant changes in its mechanical and thermomechanical properties. The tensile strength increased by $35 \%$ after irradiation at $66 \mathrm{kGy}$. Elongation decreases gradually with the irradiation dose. The lowest elongation value was registered after irradiation at $198 \mathrm{kGy}$ and reached only $25 \%$ of the elongation of a non-irradiated polymer. The E-modulus increased gradually with increasing irradiation dose. The maximum difference ( $c a .50 \%$ ) between the irradiated and non-irradiated TPE-E was measured after irradiation with 198 $\mathrm{kGy}$. Most important is the improvement in the thermal stability of TPE-E after irradiation. The tested polymer, when irradiated with $198 \mathrm{kGy}$, showed no dimensional changes, even at $250^{\circ} \mathrm{C}$. This improves the application potential of TPE-Es to areas with service temperatures much higher than their former melting-point. The micro-hardness measurements showed that irradiation also partly affects the properties of the surface layers. Irradiation is also a method that reduces the creep behaviour of the studied polymer. The resistance to creep of the crosslinked TPE-Es, increases with increasing irradiation dose.

\section{ACKNOWLEDGEMENTS}

This paper is supported by the Czech Ministry of Industry of Czech Republic in the R \& D project development of a system for hardness testing with particular emphasis on new possibilities of polymer material characteristics analysis and applications of the results to the market. FR-TI1/487, Czech Ministry of Education, Youth and Sports in the project CEBIA Tech No CZ.1.05/2.1.00/03.0089 and by the internal grant of TBU in Zlín No IGA/FT/2012/041.

\section{REFERENCES}

1. J.G. Drobny, Radiation Technology for Polymers, Boca Raton: CRC Press (2003), ISBN 1-58716-108-7.

2. BGS-Beta Gama Service. [online].<http://bgs.eu>

3. R.J. Woods, Applied Radiation Chemistry: Radiation Processing, A WileyInterscience publication, New York (1994), ISBN 0-471-54452-3.

4. M. Manas, M. Stanek, D. Manas, S. Sanda, Z. Holik and M. Danek, Chemicke listy, 105(S), S254 (2011).

5. Z. Holik, M. Danek, M. Manas, R. Lamborova, J. Cerny, K. Kyas, M. Krumal and M. Malachova, Chemicke listy, 105(S), S269 (2011).

6. Z. Brocka, Werkstoff-und Einsatzpotential strahlenvernetzter Thermoplaste, Lehrsthul für Kunststofftechnik (LKT), Nürnberg (2008).

7. J.G. Drobny, Handbook of Thermoplastic Elastomers, William Andrew Publishing, Norwich, NY (2007). ISBN: 978-0-8155-1549-4

8. PTS-Plastic Technology Service [online] (2009); [cit.2009-12-22]. $<$ http://www.pts-marketing.de/> 